\title{
R-Expressions and the Interrogative Use of Anaphora in Najdi Arabic
}

\author{
Mahmoud S. Al Mahmoud \\ Department of English, Imam University \\ Riyadh, Saudi Arabia \\ E-mail: msmahmoud@imamu.edu.sa
}

Received: July 8, 2020

Accepted: August 25, 2020

Published: September 7, 2020

doi:10.5296/ijl.v12i5.17503

URL: https://doi.org/10.5296/ijl.v12i5.17503

\begin{abstract}
This paper endeavors to explain how Najdi Arabic (NA), one of the dialects spoken in the central region of the Arabian Peninsula, diverges from Modern Standard Arabic (MSA) in its anaphoric treatment of R-expressions and pronominals. Data from a native Najdi Arabic informant suggest that only a subset of NA verbs allow proper names to be referentially bound by their antecedent pronouns in interrogative structures. Although this property is characteristic of Najdi Arabic not MSA, it yields certain challenges to the basic tenets of the Binding Theory. While Principle $\mathrm{C}$ of the Binding Theory requires R-expressions to be free, a referential reading of the NA data, which syntactically binds proper names with their pronominal referents, violates such principle.
\end{abstract}

Keywords: Najdi Arabic, Anaphora, R-expressions, Interrogative, Binding theory

\section{Introduction}

While most of the literature on the semantic nature of anaphors in Arabic is devoted to Classical Arabic (Abdul-Ghany, 1981), or Modern Standard Arabic (MSA), many grammatical aspects of Arabic dialects remain unstudied. This paper examines the use of anaphoric pronominals as interrogatives in Najdi, one of the widely-spoken dialects of Arabic. Arabic is the native language for over 186 million speakers and the liturgical one of almost 250 million people, ranking the sixth among the widely spoken languages of the world. It belongs to the Semitic group of languages and is closely related to Hebrew, Aramaic, Amharic (spoken in Ethiopia), and Tigrigna (spoken in Eritrea) (Versteegh, 2014). Najdi Arabic (NA), however, is far more limited in its use and is the native dialect of the people in the central region of the Arabian Peninsula, nowadays Saudi Arabia. 
The paper discusses how the treatment of anaphora in NA differs from that of MSA. While NA utilizes pronouns, and more specifically pronominals, to formulate questions, such usage is not possible in MSA. This emergent construction of interrogatives in NA presents certain challenges to the tenets of the Binding Theory (Haegeman, 1994; Grohmann, Hornstein, and Nunes, 2005). It is shown that while the Binding Theory succeeds in accounting for the (un) grammaticality of anaphoric relations in MSA, it comes short of explaining similar cases in NA. The paper argues that while syntactic binding in and of itself is insufficient to account for the emergent NA data, the Binding Principle when invoked maximally can offer a simple and straightforward analysis.

\section{Statement of the Problem}

A 29-year-old native speaker of the Najdi Arabic dialect provided the data for this research paper. The informant has lived in the central region of Najd, in the city of Riyadh for most of his life. His knowledge of both standard and dialectal Arabic is exemplary as his college major was Arabic. The informant was queried by the researcher himself on various constructions and possible utterances of standard as well as Najdi Arabic and his responses were recorded and analyzed.

According to the data provided by the informant, the following example in (1) best describes a question on whether someone has arrived or not in MSA:

hal
Q-word

dza?-a

arrived-mas

Ali?

Ali?

'Did Ali arrive?'

The question word hal in (1) is used to construct the interrogative and can be interpreted to mean 'did' here. The verb dza? 'arrived' is in the simple past tense, and is suffixed by the masculine clitic - $a$ through subject-verb agreement in gender. Verbs in Arabic are strong so there is no need for an auxiliary verb in question formation. The construction in (1) is uttered with a rising intonation, as is the case with all questions set off by the question word hal. The $\mathrm{R}$ (eferring)-expression Ali (all proper names are R-expressions) is used referentially and its antecedent can be an individual determined by the context of speech or conversation. Similar to (1) is the construction in (2) below:
hal
dzara-t
Nurah?
Q-word
arrived-fem
Norah?

'Did Norah arrive?'

The verb in (2) carries the feminine clitic - $t$ in agreement with the R-expression Norah, which is also used referentially here.

The data also show that it is possible for the R-expressions in (1) and (2) to be replaced, although less commonly, by pronouns in MSA: 
(3)

hal

Q-word dza?-a

arrived-mas howa?

he?

'Did he arrive?'

(4) hal

Q-word dza?-at

arrived-fem hrja?

she?

'Did she arrive?'

The pronominal pronouns howa 'he' and hija 'she' in (3) and (4), respectively, make reference to an antecedent whose mention is determinable by context or previous conversation. In other words, (3) and (4) differ from (1) and (2) only in the substitution of R-expressions for pronouns.

The questions in (1) and (2), although construed in a similar fashion, can be formed differently in Najdi Arabic. According to the informant in this study, the following constructions in (5) and (6) are commonly found in everyday Najdi Arabic speech:

(hal)

(Q-word)

'Did Ali arrive?'

(6)

(hal)

(Q-word) $\mathrm{hu}_{\mathrm{i}}$

he

$$
\text { dzaa-a }
$$

arrived-mas
$\mathrm{Ali}_{\mathrm{i}}$ ?

Ali?

'Did Norah arrive?'

Note that in both (5) and (6) the question word hal is optional, albeit obligatory in all of the MSA examples (1-4) above. Interestingly, Najdi Arabic utilizes the masculine pronoun $h u$ 'he' in (5) and the feminine pronoun $h i$ 'she' in (6) to form the interrogative (Note 1). In other words, the NA pronominal pronouns $h u$ 'he' and $h i$ 'she' can function as the question word hal. In (5) the masculine pronoun $h u$ 'he' refers to the R-expression, Ali. This referential relationship is indicated by the coindexation of the proper name and the pronominal pronoun (i.e. Ali bears the same index ${ }_{i}$ as the pronoun $h u$ 'he'). Similarly, the proper name Norah in (6) is referential and coindexed with the feminine pronominal $h i$ 'she'. Note also that the verbs in (5) and (6), compared to (3) and (4), undergo glottal plosive / $/$ / deletion with the vowel /a/ lengthened (Note 2).

The NA treatment of R-expressions referenced with pronominal pronouns, which function as interrogatives, is unprecedented; and no evidence exists, according to my knowledge, of other languages that behave similarly. Data from the informant confirmed that such usage is equally common in embedded structures as well. Consider the examples (7) and (8): 


\section{Macrothink}

Pant- $\varnothing \quad$ saPalt-uh

you-mas asked-him

(hal)

(Q-word)

$\left[\mathrm{hu}_{\mathrm{i}}\right.$

dzaa-a

$\left.\mathrm{Ali}_{\mathrm{i}}\right]$ ?

'Did you ask him if Ali arrived?'

(8)

$\begin{array}{cccccc}\text { Pant- } \varnothing & \text { saPalt-ah } & \text { (hal) } & {\left[\mathrm{hi}_{\mathrm{i}}\right.} & \text { dgaa-t } & \left.\text { Nurah }_{\mathrm{i}}\right] ? \\ \text { you-mas } & \text { asked-her } & \text { (Q-word }) & {[\text { she }} & \text { arrived-fem } & \text { Norah }] ?\end{array}$

'Did you ask her if Norah arrived?'

The structures above are comprised of the main clauses ?ant- $\phi$ sa?alt-uh and Pant- $\phi$ sa?alt-ah 'you asked him/her', and the subordinate null (if) complementize phrases, namely hu dzaa-a Ali and hi dzaa-t Nurah, which are identical to the ones in (5) and (6). Both (7) and (8) are statements uttered with rising intonation to form interrogatives in the main clause and the subordinate one as well.

While the NA examples (5) and (6) are analogues to the MSA examples (1) and (2), the NA equivalence of constructions (3) and (4) is not borne out in Najdi Arabic according to informant:

(9)

$$
* \mathrm{hu}_{\mathrm{i}}
$$

he

'Did he arrive?'

(10)

she arrived-fem she?

dzaa-t $\mathrm{hu}_{\mathrm{i}}$ ?

arrived-mas he?

$\mathrm{hi}_{\mathrm{i}}$ ?

she arrived-fem she?

'Did she arrive?'

The constructions in (9) and (10) are judged ungrammatical by native speakers of Najdi Arabic. It appears that their ungrammaticality stems from the fact that the pronominal pronouns are referenced with each other within the same clausal context (i.e. governing domain); in (9) the pronoun $h u$ 'he' is tied to the other pronoun $h u$ 'he' within the same question and so is the pronoun $h i$ 'she' in (10). In other words, the antecedent of the pronominal pronoun $h u$ 'he' in (9) is the same male person, and the antecedent of the pronominal pronoun $h i$ 'she' in (10) is the same female person. It seems that the illicitness in these structures is due to both pronominal pronouns being not free within their governing domain (more on this in section 3 ).

To sum up, it is evident from the examples above in (5) and (6) that NA presents an intriguing case in which R-expressions and proper names are used referentially with pronominal pronouns within the same syntactic domain to form the interrogative. Not only is this usage deemed novel in language, it appears to be idiosyncratic of Najdi Arabic. In fact, such structures where the proper name is linked to its antecedent are judged ungrammatical in Modern Standard Arabic: 
(11) *hal

howa $_{i}$

dza?-a

$\mathrm{Ali}_{\mathrm{i}}$ ?

Q-word

he

arrived-mas

Ali?

'Did Ali arrive?'

$\begin{array}{lccc}\text { *hal } & \text { hrja }_{\mathrm{i}} & \text { dzaPa-t } & \mathrm{Nurah}_{\mathrm{i}} \text { ? } \\ \text { Q-word } & \text { she } & \text { arrived-fem } & \text { Norah? }\end{array}$

'Did Norah arrive?'

The treatment of R-expressions referentially with the pronominals presents a serious dilemma to the Binding Theory, which predicts, erroneously in case of NA, the ungrammaticality of (5) and (6). In what follows a discussion of how the Binding Theory fails to exclude such structures is presented; and what alternative analysis is possible to account for the emergence of anaphoric pronominals along with their proper name referents as a device for question formation in Najdi Arabic.

\section{Discussion}

It is important to understand before contemplating a possible explanation to the newly found syntactic configuration of NA question formation how the Binding Theory operates in anaphoric relations, and why it fails to rule out the occurrence of such structure in NA (see Hicks, 2009 for a critique of the BT).

\subsection{The Binding Theory}

The Binding Theory (BT), also known as the Government and Binding Theory (GBT), is part of a larger theoretical framework on Transformational Grammar (TG) advanced by Chomsky (1982), and later revisited in his well-acclaimed book the Minimalist Program (1995). While an extensive overview of the Binding Theory is beyond the scope of this paper, focus will be on the relevant principles and concepts of the BT germane to the issue at hand (see Büring, 2005; Haegman, 1994; Webelhouth, 1995 for in-depth discussion of the BT).

According to the Binding Theory, there are basically three conditions or states which define the binding relationship between the noun or the pronoun and its antecedent or binder, and can be formalized in the following three principles (Grohmann, Hornstein, and Nunes, 2005, p. 236):

(13) Principles of the Binding Theory

I. Principle A: An anaphor (e.g. a reflexive or reciprocal) must be bound in its domain or governing category.

II. Principle B: A pronoun must be free, not bound, in its domain or governing category.

III. Principle C: An R-expression (e.g. proper name or variable) must be free everywhere. 


\section{Macrothink}

Ancillary to the principles in (13) are the definitions in (14) and (15) below:

\section{(14) Domain}

$\alpha$ is the domain for $\beta$ if and only if $\alpha$ is the smallest IP/TP (Inflectional Phrase/Tense Phrase) containing $\beta$ and the governor of $\beta$.

\section{C-Command}

$\alpha$ c-commands $\beta$ if and only if $\alpha$ does not dominate $\beta$; $\beta$ does not dominate $\alpha$; and the first branching node dominating $\alpha$ also dominates $\beta$ (Haegeman, 1994, p. 222).

The Governing Category means the minimal or local domain that contains the governor, governee and the subject, and is often used synonymously with the term domain. Armed with these definitions, the notion of Syntactic Binding in the Binding Theory is stated as follows:

\section{Syntactic Binding}

$\alpha$ syntactically binds $\beta$ if and only if $\alpha$ c-commands $\beta ; \alpha$ and $\beta$ are co-indexed; and $\alpha$ is an A-position.

In (16) the conditions of c-command and coindexing are clear by now, but the notion of A-position needs to be clarified. While Rizzi (1991) defines A-positions as thematic positions or specifiers of Agr(eement), for Chomsky (1993) an A-position is a specifier of complement position of a feature of a lexical head. Haeberli (2002, pp. 10-11) considers A-positions as "thematic positions but also positions in the functional domain which are only occupied by arguments, such as agreement or case positions".

\subsection{R-Expressions and Pronominals in MSA vs NA}

\subsubsection{R-Expressions}

In order to appreciate the discrepancies in the behavior of R-expressions in MSA and NA interrogative structures, a reexamination of the data vis-à-vis Principle $\mathrm{C}$ of the Binding Theory is necessary. Consider the following examples from MSA, discussed earlier in section 2 and repeated here for convenience sake:

[hal

[Q-word

[dza?-a

[arrived-mas

'Did Ali arrive?'

(18)

[hal

[dzaPa-t

[Q-word

[arrived-fem
Ali?]]

Ali?]]

Nurah?]]

Norah?]]

'Did Norah arrive?'

$\begin{array}{lccc}*[\text { hal } & \text { howa }_{\mathrm{i}} & {[\mathrm{dga}-\mathrm{a}} & \left.\mathrm{Ali}_{\mathrm{i}} \text { ? }\right] \\ {[\mathrm{Q}-\text { word }} & \text { he } & {[\text { arrived-mas }} & \text { Ali?] }\end{array}$


'Did Ali arrive?'
$*[$ hal
hrja
[dza?a-t
$\operatorname{Nurah}_{i}$ ?]]
[Q-word
she
[arrived-fem
Norah?]]

'Did Norah arrive?'

Principle $\mathrm{C}$ of the Binding Theory, which states that R-expressions must be free everywhere, seems to be obeyed in (17) and (18) as the proper names Ali and Norah are not coindexed with nor are they bound by any element in the clause. However, the same is not true for (19) and (20); the binding of the R-expressions Ali and Norah by the pronouns howa 'he' and hija 'she' violates Principle $\mathrm{C}$ and renders the construction ungrammatical.

In contrast to MSA, NA allows R-expressions to be syntactically bound to the pronouns; that is to say, they are not free:

[(hal)

$[(\mathrm{Q}-$ word $)$ $\mathrm{hu}_{\mathrm{i}}$

he

'Did Ali arrive?'

(22)

$[($ hal $)$

$[(\mathrm{Q}-$ word $)$ hi $_{\mathrm{i}}$

she $\mathrm{t}_{\mathrm{i}}$

dgaa-a

[arrived-mas

[dzaa-t

[arrived-fem
$\mathrm{Ali}_{\mathrm{i}}$ ?]]

Ali?]]

$\operatorname{Nurah}_{\mathrm{i}}$ ?]]

Norah?]]

'Did Norah arrive?'

To illustrate the syntactic binding relationship between the R-expressions and the pronouns in (21) and (22), consider the following tree structure diagrams:

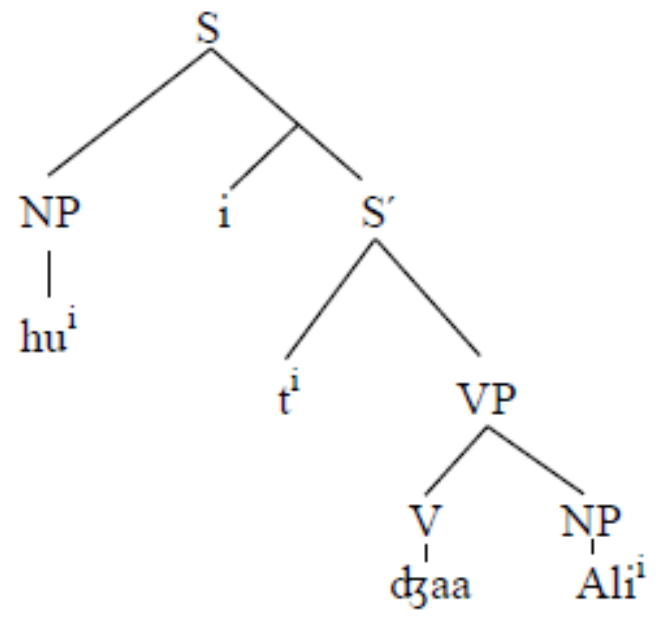

Figure 1. Binding between R-expression Ali and Pronoun $h u$ 'he' 


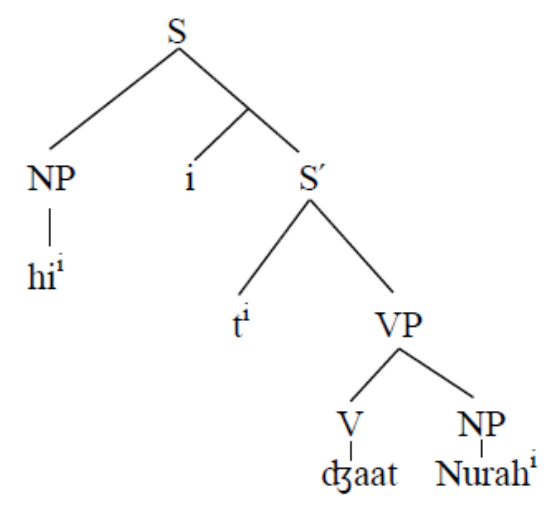

Figure 2. Binding between R-expression Nurah and Pronoun $h i$ 'she'

All conditions for syntactic binding are met in Figures 1 and 2. Assuming that the Binding Theory accounts only for bound variables, the pronouns $h u$ 'he' in Figure 1 and $h i$ 'she' in Figure 2 must raise to the quantifier position in the tree structure, the NP head position, leaving a trace behind (for further discussion on Quantifier Raising, see Heim and Kratzer, 1998). The A-position pronominals $h u$ 'he' and $h i$ 'she' c-command the R-expressions Ali and Norah respectively since neither one dominates the other. The R-expressions are referentially coindexed with the pronouns. More specifically, the syntactic binding here occurs between the trace of the pronominal and the proper name, both assigned the same indexation $i$. Regardless of whether the binding is local and operates within the governing category or not, examples (21) and (22) constitute a clear violation of Principle C, and should not, therefore, surface in language. In other words, the Najdi Arabic structures (21) and (22), contrary to the MSA examples (17) and (18), should be deemed ill-formed, yet they are reported by the informant to be fully acceptable by native speakers of Najdi Arabic.

To sum up, it seems that while MSA systematically obeys Principle $\mathrm{C}$ of the Binding Theory as examples (17-20) demonstrate, NA allows structures that are otherwise prohibited by Principle C; hence, a stark discrepancy between MSA and NA exists in the treatment of R-expressions.

\subsubsection{Pronominals}

A cursory look at examples (3), (4), (9) and (10) reveals that in the treatment of pronominals both MSA and NA abide by Principle B of the Binding Theory. Consider (3) and (4), repeated here as (23) and (24):

(23) hal

Q-word howa?

he?

'Did he arrive?'

(24) hal

$$
\text { dza?-at hija? }
$$

Q-word

arrived-fem

she? 


\section{Macrothink}

Note how the pronouns howa 'he' and hija 'she', as evidenced by lack of coindexation, are not bound in their governing category, in accordance with Principle B of the Binding Theory; that is, they do not refer to an entity within the clause. Likewise, the examples (9) and (10), repeated here as (25) and (26), show that NA, in line with Principle B, does not permit pronouns to be bound within their governing domains:

$* \mathrm{hu}_{\mathrm{i}}$

he

dgaa-a

arrived-mas

$\mathrm{hu}_{\mathrm{i}}$ ?

'Did he arrive?'

$\begin{array}{ccc}* \mathrm{hi}_{\mathrm{i}} & \text { dzaa-t } & \mathrm{hi}_{\mathrm{i}} \text { ? } \\ \text { she } & \text { arrived-fem } & \text { she? }\end{array}$

'Did she arrive?'

The following diagrams demonstrate the binding relationships between the pronouns in (25) and (26):

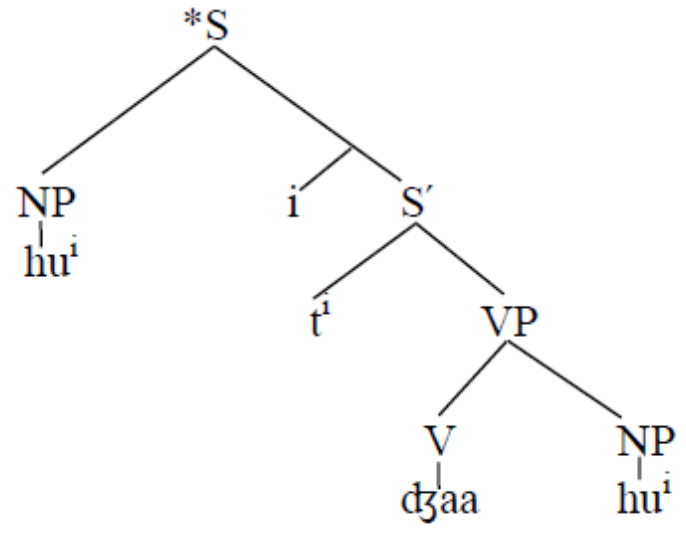

Figure 3. Binding between Post Verbal Pronoun $h u$ 'he' and Preverbal one

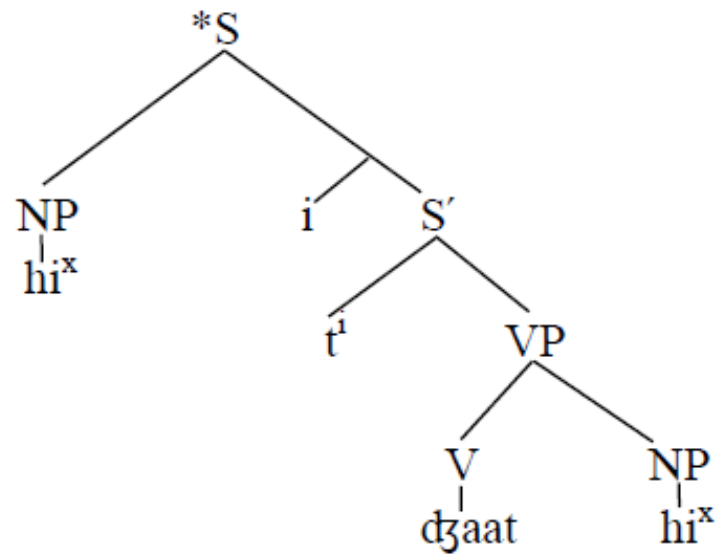

Figure 4. Binding between Post Verbal Pronoun $h i$ 'she' and Preverbal one 


\section{Macrothink}

(25) and (26) are ungrammatical because the pronouns are not free as they are used referentially. Figures 3 and 4 show how the post verbal pronouns $h u$ 'he' and $h i$ 'she' are coindexed and c-commanded by the preverbal ones; i.e. both pronouns refer to each other and both refer to the same person.

\subsubsection{R-expressions and Verb Transitivity (Note 3)}

Further examination of the data provided by the informant reveals some interesting distribution restrictions on the referential use of R-expressions in Najdi Arabic. Recall that contrary to Principle C of the BT, Najdi Arabic permits R-expressions to be bound as argued in 3.2.1. Nonetheless, data elicited from the informant suggest that this referential treatment is only possible with intransitive verbs:

$\begin{array}{lll}* \mathrm{hu}_{\mathrm{i}} & \underline{\text { tarab }} & \mathrm{Ali}_{\mathrm{i}} ? \\ \text { he } & \text { hit-mas } & \text { Ali? }\end{array}$

'Did Ali hit (someone or something)?'

$\begin{array}{ccc}* \text { hi }_{\mathrm{i}} & \text { tarab-at } & \text { Nurah }_{\mathrm{i}} ? \\ \text { she } & \text { hit-fem } & \text { Norah? }\end{array}$

'Did Norah hit (someone or something)?'

In (27) and (28) the R-expressions Ali and Norah refer to $h u$ 'he' and $h i$ 'she', respectively, but because the verb tarab 'hit' is transitive, the structures are impossible in NA. This is reasonable since the verb tarab 'hit' requires an object different from the subject $h u$ 'he'/hi 'she'; i.e. the subject and object cannot refer to the same person.

In order to render examples (27) and (28) acceptable, either the verb becomes intransitive, as in (21) and (22) (the verb dzaa 'arrived' requires no object), or the R-expression has to be free of binding:

$\begin{array}{ccc}\mathrm{hu}_{\mathrm{i}} & \text { tarab } & \text { Ali? } \\ \text { he } & \text { hit-mas } & \text { Ali? }\end{array}$

'Did he hit Ali?'

(30) $\mathrm{hu}_{\mathrm{i}}$

tarab

Ali.

he

hit-mas

Ali.

'He hit Ali.'

$\mathrm{hi}_{\mathrm{i}}$

tarab-at

Nurah?

she

hit-fem

Norah?

'Did she hit Norah?' 
(32) $\quad \mathrm{hi}_{\mathrm{i}}$

tarab-at

Nurah.

she

hit-fem

Norah.

'She hit Norah.'

Note that a referential reading where Ali and Norah are related to the pronouns $h u$ 'he' and $h i$ 'she' is not possible here regardless whether the structure is interrogative or declarative. The pronouns are indexed with the subject (a person specified by the context of speech). The proper names Ali and Norah serve as the object of the verb tarab 'hit'. In other words, the antecedents of the pronominals $h u$ 'he' and $h i$ 'she' must not be the same individuals to whom the R-expressions refer. The antecedents have to be other individuals (or things) that are salient in the conversation and are believed to be the agent of the action.

Aside from the fact that they violate Principle C of the BT, one reason for the unacceptability of (27) and (28) in the first place is the semantic ambiguity that arises with such structures since the pronouns $h u$ 'he' and $h i$ 'she' can have multiple readings:

A. Be indexed and referential with the R-expressions as in (27) and (28). In this case, the construction has to be a question about the subject proper name mentioned in the sentence. The sentence then carries the meaning of confirmation and is deemed ungrammatical.

B. Be referential with a subject not mentioned in the sentence. In this case, the construction can either be a question asking about the subject as in (29) and (31), or a declarative statement about the subject, informing us that someone hit Ali or Norah as in (30) and (32).

In other words, when the R-expression is the subject, a referential reading with the pronoun is construed. But when the R-expression is the object, a reading of a declarative or a question about a subject not present in the sentence is obtained.

The NA idiosyncrasy in the use of anaphoric R-expressions can be summarized as follows:

(33) Intransitive verbs allow reference of R-expressions with pronouns; such verbs include: naam 'slept', raa $\underline{h}$ 'went', fakkar 'thought', rakad 'ran', qaam 'stood', baka 'cried', daras 'studied', ta?allam 'suffered'....etc.

(34) Transitive verbs with which R-expressions have to be free (not coindexed with pronouns); such as: qatal 'killed', faaf 'saw', dzarah 'injured', dzarrab 'tried', darras 'taught'...etc.

However, consider the following set of sentences:

$\begin{array}{llr}\mathrm{hu}_{\mathrm{i}} & \text { Pakal } & \mathrm{Ali}_{\mathrm{i}} \text { ? } \\ \text { he } & \text { ate-mas } & \text { Ali? }\end{array}$

'Did Ali eat?' 
$\mathrm{hi}_{\mathrm{i}}$

she

$\mathrm{Nurah}_{\mathrm{i}}$ ?

Norah?

'Did Norah eat?'

$\begin{array}{lll}* \mathrm{hu}_{\mathrm{i}} & \text { Pakal } & \text { Ali? } \\ \text { he } & \text { ate-mas } & \text { Ali? }\end{array}$

'Did he eat Ali?'

$\begin{array}{ccc}* \mathrm{hi}_{\mathrm{i}} & \text { Pakal-at } & \text { Nurah? } \\ \text { she } & \text { ate-fem } & \text { Norah? }\end{array}$

'Did she eat Norah?'

Even though the verb ?akal 'ate' is transitive, the R-expressions Ali and Norah must be coindexed with the pronouns. According to (34) and Principle C of the BT, neither (35) nor (36) should exist in NA, but the informant in this study emphasized their grammaticality. Two readings for the aforementioned construction are possible:

A. A referential reading where the pronouns refer to the agentive R-expressions as in (35) and (36); this is the most natural and acceptable reading obtainable.

B. The R-expressions are free and the pronouns refer to someone else as in (37) and (38); in this case, the questions inquire whether someone ate Ali and Norah. Such reading is fortunately not acceptable and can only be true in a world where humans are eatable!

But how is it that some verbs, although transitive, can permit such constructions while others such as the ones in (34) do not? It is argued that the two verbs tarab 'hit' and Pakal 'ate' behave differently when it comes to the choice of object they take: while in every day speech, the verb tarab 'hit' can take both human and nonhuman objects, the verb ?akal 'ate' is restricted to nonhuman objects. Other verbs that fit into this category include: farab 'drank',

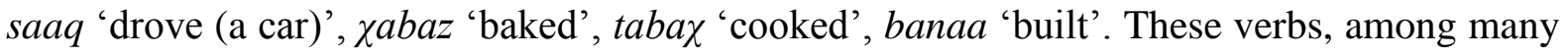
others, would allow R-expressions to be referential with the pronouns to form interrogatives since no ambiguous reading can arise: such verbs must only take nonhuman objects, and the pronouns $h u$ 'he' and $h i$ 'she' have to refer to the R-expressions within the sentence.

\subsection{Analysis}

The discussion so far can be summarized as follows; MSA treats pronouns and R-expressions in accordance with Principles $\mathrm{B}$ and $\mathrm{C}$ of the Binding Theory while NA employs R-expressions referentially, in violation of Principle C. While no clear explanation for the referential behavior of R-expressions in NA exists, a number of possible arguments can be entertained.

One possible analysis is to consider examples (21) and (22), repeated here as (39) and (40), as instances of apposition: 


\section{Macrothink}

[(hal)

$[(\mathrm{Q}-$ word $)$

$$
\mathrm{hu}_{\mathrm{i}}
$$

he

2020, Vol. 12, No. 5

'Did Ali arrive?'

$\begin{array}{lllll}{[(\text { hal })} & \text { hi }_{i} & \mathrm{t}_{\mathrm{i}} & \text { [dzaa-t } & \text { Nurah }_{\mathrm{i}} \text { ?] } \\ {[(\mathrm{Q}-\text { word })} & \text { she } & & \text { [arrived-fem } & \text { Norah?]] }\end{array}$

'Did Norah arrive?'

Apposition can be defined as "a relation consisting of two units that are coreferential" (Meyer, 2007, p. 57). However, apposition is ruled out since the R-expressions and the pronominals in these examples are not adjacent (see Bloch, 1991 and Meyer, 2007 for in-depth discussion of apposition and pronoun reduplication). An alternative analysis is to regard the NA phenomenon as a case of left-periphery. However, the constructions in (39) and (40) above are uttered with no pause between the pronouns $h u$ 'he' and $h i$ 'she' and the rest of the sentence. In fact, left-peripheries do exist in Najdi Arabic and have their own distinct construction:

$\begin{array}{lll}\text { Ali }_{\mathrm{i}}, & \mathrm{hu}_{\mathrm{i}} & \text { dzaa-a? } \\ \text { Ali, } & \text { he } & \text { arrived-mas? }\end{array}$

'Ali, did he arrive?'

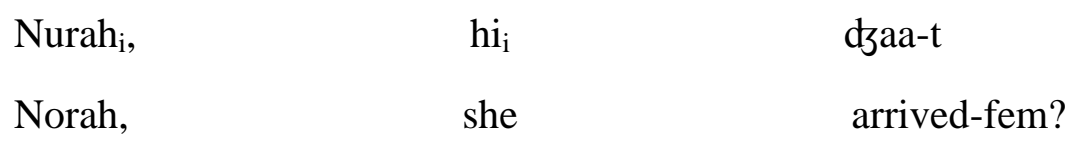

'Norah, did she arrive?'

Note how a pause exists (as indicated by the comma placement) after the R-expressions Ali and Norah.

The inadequacy of Principle C of the BT in explaining the grammaticality of (39) and (40) suggests that syntactic binding by itself is not sufficient. Another principle that interacts with the BT and involves syntactic as well as semantic binding is invoked:

\section{Binding Principle}

$\alpha$ binds $\beta$ syntactically at SS iff $\alpha$ binds $\beta$ semantically at LF.

The BP requires that whenever there is syntactic binding between two elements at the Surface Structure (SS), there has to be semantic binding between them at the Logical Form (LF). In other words, if syntactic binding exists, then semantic binding does and vice versa. The Binding Principle also implies that syntactic binding or lack of it has no effect on reference interpretations.

Armed with this notion, the examples in (39) and (40) can be reanalyzed in accordance with the BP. Recall that a bound variable interpretation, where the R-expressions Ali and Norah 
are c-commanded and syntactically bound by the trace of the pronominal pronouns $h u$ 'he' and $h i$ 'she', yields unsatisfactory results and ultimately fails to rule out such structures. If, however, the relationship between the R-expressions and the pronominals is presumed to be of coreference, such structures can be ruled in. Consider the following examples where the $\mathrm{R}$-expressions and the pronominal pronouns are assigned two distinct indices:

$[($ hal $)$

[(Q-word) $\mathrm{hu}_{\mathrm{x}}$

he $t_{i}$

[arrived-mas
$\mathrm{Ali}_{\mathrm{z}}$ ?]]

Ali?]]

'Did Ali arrive?' $\operatorname{hi}_{\mathrm{x}}$

she $t_{i}$

[(Q-word) [dzaa-t

[arrived-fem
$\operatorname{Nurah}_{z}$ ?]]

Norah?]]

'Did Norah arrive?'

According to (16), the R-expression and the pronoun must be coindexed (i.e. assigned the same index value) for Syntactic Binding to take place. In (44) and (45), there is no Syntactic Binding as the pronouns $h u$ 'he' and $h i$ 'she' carry the variable ${ }_{\mathrm{x}}$, whereas the proper names Ali and Norah are indexed with ${ }_{\mathrm{z}}$. It is hypothesized then that the coreferential relationship between the R-expressions and the pronouns is arbitrary; both happen to refer to the same entity (see Heim and Kratzer, 1998 on the analysis of Identity Conditions and the discussion therein).

\section{Conclusion}

This paper unraveled an emergent linguistic phenomenon, previously undocumented in the Najdi Arabic dialect of the Arabian Peninsula. A native Najdi informant provided valuable data for the interrogative usage of R-expressions and pronominals in NA. In contrast with MSA, NA's employment of R-expressions referentially when forming questions raises concerns about the adequacy of Principle $\mathrm{C}$ of the Binding Theory in the exclusion of such constructions. It is further argued that the intricate choice of verb with regard to transitivity plays an important role: only intransitive verbs and verbs with nonhuman objects can permit R-expressions to be bound to the pronouns. It is proposed that, in line with the Binding Principle where semantic binding follows as a corollary of syntactic binding, the treatment of $\mathrm{R}$-expressions in NA is a result of a random coreference relationship with the pronominals.

\section{References}

Abdul-Ghany, M. (1981). Government binding in classical Arabic. Doctoral Dissertation, University of Texas, Austin.

Bloch, A. (1991). Studies in Arabic syntax and semantics. Otto Harrassowitz: Wiesbaden.

Büring, D. (2005). Binding theory. Cambridge University Press. https://doi.org/10.1017/CBO9780511802669 


\section{Macrothink}

International Journal of Linguistics

ISSN 1948-5425

2020, Vol. 12, No. 5

Chomsky, N. (1982). Some concepts and consequences of the theory of government and binding. MIT Press: Cambridge, Massachusetts.

Chomsky, N. (1993). A minimalist program for linguistic theory. MIT Occasional Papers in Linguistics, 1-67.

Chomsky, N. (1995). The minimalist program. MIT Press: Cambridge, Massachusetts.

Grohmann, K., Hornstein, N., \& Nunes, J. (2005). Understanding minimalism. Cambridge University Press. https://doi.org/10.1017/CBO9780511840678

Haeberli, E. (2002). Features, categories and the syntax of A-positions. Cross-linguistic variation in the Germanic languages. Dordrecht: Kluwer. https://doi.org/10.1007/978-94-010-0604-0

Haegeman, L. (1994). Introduction to government and binding theory. Oxford: Blackwell.

Heim, I., \& Kratzer, A. (1998). Semantics in generative grammar. Blackwell Publisher Ltd: Malden, Massachusetts.

Hicks, G. (2009). The derivation of anaphoric relations. Amsterdam: John Benjamins. https://doi.org/10.1075/la.139

Hualde, J. (1990). Compensatory lengthening in Friulian. Probus, 2(1), 31-46. https://doi.org/10.1515/prbs.1990.2.1.31

Meyer, C. (2007). Apposition in contemporary English (Studies in English language). Cambridge University Press.

Poser, W. (1988). Glide formation and compensatory lengthening in Japanese. Linguistic Inquiry, 19(3), 494-503. Retrieved from www.jstor.org/stable/25164907

Rizzi, L. (1991). Proper head government and the definition of A-positions. Paper presented at the GLOW conference, Leiden.

Sukač, R. (2011). Compensatory lengthening in West Slavic. Zeitschrift Für Slawistik, 56(4), 417-445. https://doi.org/10.1524/slaw.2011.0041

Versteegh, K. (2014). The Arabic language. Edinburgh University Press Ltd: UK.

Webelhouth, G. (1995). Government and binding theory and the minimalist program: Principles and parameters in syntactic theory. Publisher: Wiley-Blackwell.

\section{Notes}

Note 1. MSA pronoun forms howa 'he' and hija 'she' undergo glide deletion and vowel lengthening in NA and are realized as $h u$ 'he' and $h i$ 'she'. 


\section{Macrothink}

International Journal of Linguistics

ISSN 1948-5425 2020, Vol. 12, No. 5

Note 2. Although irrelevant to the current discussion, this process of Compensatory Lengthening is quite common in Najdi Arabic and is found in a number of other languages as well (see for example Hualde, 1990; Poser, 1988; Sukač, 2011; among many others).

Note 3. Needless to say, pronominal pronouns in NA have to obey Principle B of the Binding Theory irrespective of verb transitivity:
A. $* \mathrm{hu}_{\mathrm{i}}$
dzaa-a
$\mathrm{hu}_{\mathrm{i}}$ ?
B. $* \mathrm{hu}_{\mathrm{i}}$
tarab
$\mathrm{hu}_{\mathrm{i}}$ ?
he
arrived-mas
he?
he
hit-mas
he?

'Did he arrive?'

'Did he hit (someone or something)?'

Both sets of examples here are violations of Principle B of the BT, and are considered ungrammatical by native speakers of NA.

\section{Copyrights}

Copyright for this article is retained by the author(s), with first publication rights granted to the journal.

This is an open-access article distributed under the terms and conditions of the Creative Commons Attribution license (http://creativecommons.org/licenses/by/4.0/) 